\title{
6. INFLUENCE OF DRILLING ON TWO RECORDS OF THE MATUYAMA/BRUNHES POLARITY TRANSITION IN MARINE SEDIMENT CORES NEAR GRAN CANARIA ${ }^{1}$
}

\author{
B. Herr, ${ }^{2}$ M. Fuller, ${ }^{3}$ M. Haag, ${ }^{4}$ and F. Heider ${ }^{2}$
}

\begin{abstract}
Two records of the Matuyama/Brunhes transition were obtained from the Ocean Drilling Program (ODP) at Sites 953 and 954, which were drilled in the volcanic apron of Gran Canaria in the Canary Islands. Rock magnetic analyses revealed magnetic carriers close to magnetite in composition and in the pseudo-single-domain grain-size range. The transitions were sampled with u-channels and with discrete samples that were taken on both sides of the u-channels covering the transitional region. Each core exhibits a stable record of the geomagnetic transition. Assuming a dipolar field, the virtual geomagnetic pole (VGP) starts at high southern latitudes and ends with well-established VGPs in high northern latitudes.

However, there is a large difference of nearly $60^{\circ}$ in the longitude of the VGP paths from the two sites. This difference is not the result of different field directions at the two localities, because the sites are only $48 \mathrm{~km}$ apart. The remanent magnetization of the discrete samples taken alongside the u-channels is demonstrably contaminated with a drilling-produced magnetic remanence with a horizontal component that is directed radially inward and hard to demagnetize. In addition, a much softer drill moment was observed that is directed steeply downward. The radial character of the magnetic overprint was found because the samples were taken on both sides of the u-channels. Even in the u-channels taken from the center of the core section, the horizontal radial moment appears to be present. The demagnetization characteristics of the radial moment are comparable to the natural remanent magnetization. The presence of the pervasive drill moments and their ability to introduce false transitional points in the reversal records suggest caution in the interpretation of ODP reversal records, which have not been adequately tested for the presence of such drilling-produced overprints.
\end{abstract}

\section{INTRODUCTION}

Our initial aim for this study was to obtain geomagnetic transitional records of the Matuyama/Brunhes field transition. During Ocean Drilling Program (ODP) Leg 157, two sites, 953 and 954, were drilled north of Gran Canaria into the volcanic apron that surrounds the Canary Islands. Both sites are only $48 \mathrm{~km}$ apart, and the distance to the coastline of Gran Canaria is $68 \mathrm{~km}$ (953) and $34 \mathrm{~km}(954)$, respectively.

Geomagnetic reversal records are a subject of intense scientific activity, and the interpretation and determination of the transitional field behavior remains highly controversial. Clement (1991), Laj et al. (1991), and Tric et al. (1991) published evidence for geomagnetic field reversals that followed preferred longitudinal virtual geomagnetic pole (VGP) paths across the Americas and the antipode. The hypothesis of preferred longitudinal paths has been strongly criticized on a statistical basis by Valet et al. (1992) and McFadden et al. (1993). These authors showed that VGP paths, which are confined to the longitudinal band across the Americas, tend to lie $90^{\circ}$ away from their related site longitudes. This argument was opposed by Laj et al. (1992), who used standard methods of statistical distributions on a circle for the same data set that was used by Valet et al. (1992). It was shown that there is a dominance of transitional VGP paths over the Americas and, to a lesser extent, over the antipode. The reliability of sediments to record the direction of the Earth's field was questioned

${ }^{1}$ Weaver, P.P.E., Schmincke, H.-U., Firth, J.V., and Duffield, W. (Eds.), 1998. Proc. ODP, Sci. Results, 157: College Station, TX (Ocean Drilling Program).

Institut für Allgemeine und Angewandte Geophysik, Ludwig-MaximiliansUniversität, Theresienstrasse 41, 80333 München, Federal Republic of Germany. beru@ rockmag.geophysol.und.mueuchen

${ }^{3}$ Department of Geological Sciences, University of California, Santa Barbara, CA 93106, U.S.A. (Present address: SOEST-Hawaii Institute of Geophysics and Planetology, University of Hawaii, Honolulu, HI 96822, U.S.A.).

${ }^{4}$ Centre des Faibles Radioactivites, Laboratoire mixte CNRS-CEA, 91198 Gif-SurYvette Cedex, France (Present address: Institutfür Geophysik, ETH-Hönggerberg, 8093 Zurich, Switzerland). by Langereis et al. (1992), Quidelleur and Valet (1994), and Kent and Schneider (1995). However, considering the huge number of sedimentary transitional records from drilled marine sediments, only a few authors (e.g., Bleil, 1989; Shipboard Scientific Party, 1995; Roberts at al., 1996; and Fuller et al., Chap. 5, this volume), have investigated the influence of drilling on the magnetization of sediment cores. These overprints are usually considered to be weak in magnetization and easy to remove. It was shown that split core sections, even after demagnetization at $25 \mathrm{mT}$, still show magnetic overprints (Fuller et al., Chap. 5, this volume) which sometimes made magnetostratigraphic work impossible with data obtained from whole core measurements (Shipboard Scientific Party, 1995). In this study, we show that even when the transitional record appears to be free from drilling influence, there are still secondary components of magnetization left that tend to bias the directional transitional field record.

\section{EXPERIMENT}

Two records of the Matuyama/Brunhes transition from Holes 953A and 954A were sampled with 1.5-m-long $\mathrm{u}$-channels and with discrete samples taken alongside the u-channels across the transitional interval. The split core sections sampled include Sections 157953A-5H-4 and 157-954A-7H-2. Discrete samples were taken from the core intervals $157-953 \mathrm{~A}-5 \mathrm{H}-4,54.9-67.8 \mathrm{~cm}$, and from $157-$ $954 \mathrm{~A}-7 \mathrm{H}-2,61.6-80.4 \mathrm{~cm}$. The cross section of the u-channels is 2 $\times 2 \mathrm{~cm}^{2}$. The u-channels were measured at $1-\mathrm{cm}$ intervals with a $2 \mathrm{G}$ cryogenic magnetometer in Gif-Sur-Yvette (France). The system was described by Weeks et al. (1993). The natural remanent magnetization (NRM) was stepwise demagnetized using alternating magnetic fields (AF). After measuring the initial susceptibility $(\kappa)$, an anhysteretic remanence (ARM) was applied at $100 \mathrm{mT}$ AF field with a bias field of $0.05 \mathrm{mT}$ and demagnetized successively. Finally, a saturation isothermal remanent magnetization (SIRM) was given to the u-channels in a 560-mT direct field followed by stepwise AF demagnetization. The volume of the cylindrical discrete samples was

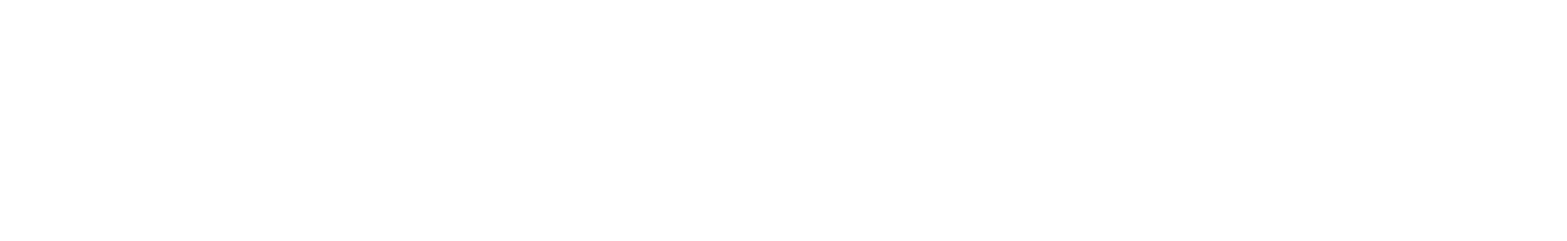


$3.7 \mathrm{~cm}^{3}$ with a diameter of $1.8 \mathrm{~cm}$. The NRM of the discrete samples was measured and stepwise AF demagnetized. The initial susceptibility $\kappa$ and the anisotropy of magnetic susceptibility (AMS) were measured with a KLY 2 Kappabridge. An ARM and a SIRM was given to the single specimens, and each type of magnetization was $\mathrm{AF}$ demagnetized. The remanence coercive force $\left(\mathrm{H}_{\mathrm{CR}}\right)$ of the discrete samples was determined with the backfield method after saturation at $1.5 \mathrm{~T}$. The hysteresis parameters were measured using a Molspin vibrating sample magnetometer. Saturation magnetization was determined with a Curie balance as a function of temperature to obtain the Curie points $\left(\mathrm{T}_{\mathrm{C}}\right)$ of the bulk sediment.

\section{RESULTS}

\section{Mineral Magnetic Nature of the Magnetic Carriers}

The main lithology of the cores recovered from Holes 953A and 954A is pelagic nannofossil ooze with some clay content. With the exception of one altered ash layer at the bottom of both u-channels, the sediment seems to be very homogeneous, which we interpret as an indication of continuous sedimentation. Bioturbation in the sediment is moderate. A typical result of the Curie point analysis is shown in Figure 1. Curie temperatures between $560^{\circ}$ and $570^{\circ} \mathrm{C}$ were obtained, typical for magnetite or titanomagnetite with very low titanium content. The shape of the curve in Figure 1 indicates no evidence for Curie points at lower or higher temperatures. In Figure 2, the results of the hysteresis and backfield experiments are summarized. The grain sizes are in the pseudo-single-domain range according to Day et al. (1977). The ratio of the saturation remanent magnetization to saturation magnetization $\left(\mathrm{M}_{\mathrm{RS}} / \mathrm{M}_{\mathrm{S}}\right)$, as well as the ratio between remanence coercive force and coercive force $\left(\mathrm{H}_{\mathrm{CR}} / \mathrm{H}_{\mathrm{C}}\right)$, are an indication for the domain state of the magnetic carrier. The $M_{R S} / M_{S}$ ratios vary between 0.15 and 0.25 , and for the $\mathrm{H}_{\mathrm{CR}} / \mathrm{H}_{\mathrm{C}}$ ratio, we obtained a range from 2.5 to 3.5. For Site 954, the ratios indicate slightly larger grain sizes of the magnetite particles, which can be explained with the shorter distance to the volcanic source so that large grains were still suspended in the sediment transport currents.

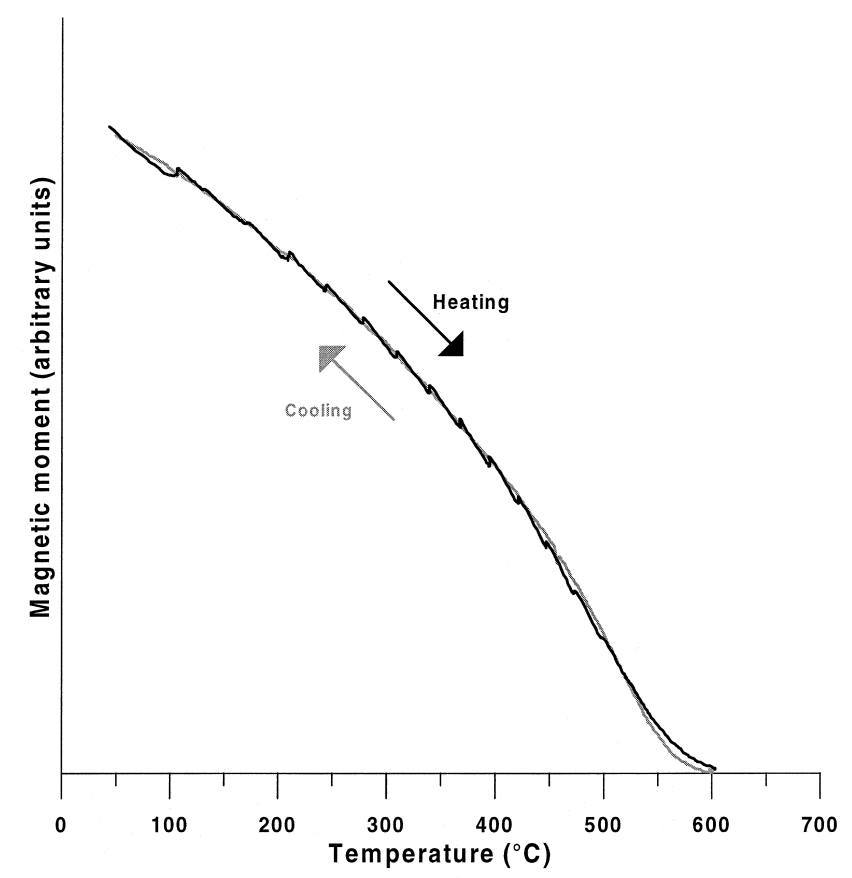

Figure 1. Saturation magnetization as a function of temperature of a representative sample. The "saw-tooth" shape of the heating curve (black line) is caused by the limping effects of the heating.
The grain-size-related behavior of the u-channel samples was analyzed using a diagram in which ARM intensity is plotted vs. the initial susceptibility $\mathrm{K}$ (Figs. 3 , 4). The positions of the measured intervals in the u-channels are used to plot the values, and there is a large loop in the ARM vs. $\kappa$ records between 99 and $109 \mathrm{~cm}$ at Site 953 (Fig. 3), and an even larger loop between 119 and $136 \mathrm{~cm}$ at Site 954 (Fig. 4). These loops coincide with the dark layers of crystal lithic sand. Although the loop indicates mainly strong changes in the magnetic concentration at Site 953, changes in chemical composition cannot be excluded for Site 954. The intervals in the vicinity of these layers and below were excluded from further analysis. The core intervals above these layers show mainly changes in the concentration of magnetic grains with only minor indications for changes in grain size and/or chemical composition.

Further observations of changes in magnetic grain size along the u-channels are provided in Figures 5 and 6. Both diagrams show at the top the variation of the ARM/SIRM and $\kappa_{\mathrm{ARM}} / \kappa$ ratios at the same demagnetization levels vs. u-channel depth. Higher values for the $\kappa_{\mathrm{ARM}} / \mathrm{K}$ and ARM/SIRM ratios indicate smaller grain sizes (Bloemendal et al., 1992). In contrast to the ARM/SIRM ratio, the $\kappa_{\mathrm{ARM}} / \kappa$ ratio can be disturbed by changes of the para- and/or diamagnetic mineral content. Two estimates of relative paleointensities are provided below these records. To obtain relative geomagnetic field intensities from sedimentary rocks, it is necessary to normalize the NRM intensity with a parameter that is related to the concentration of the magnetic material (Tauxe, 1993). The estimates of relative paleointensities in Figures 5 and 6 were obtained by using values of NRM, ARM, and IRM intensities at their equivalent demagnetization steps $(50 \mathrm{mT}$ for Site 953 and $20 \mathrm{mT}$ for Site 954). These are the AF demagnetization levels, where the reversed and normal polarity pre- and posttransitional became antipodal. To observe the paleointensity behavior in relation to the reversing field, the calculated VGP latitudes are presented. The headers of Figures 5 and 6 provide a description of the core lithology. The core sections from Sites 953 and 954 are similar except for one crystal lithic silt layer at $32 \mathrm{~cm}$ in Section 157-954A$7 \mathrm{H}-2$. The areas where discrete samples were taken are emphasized by black bars in Figures 5 and 6 .

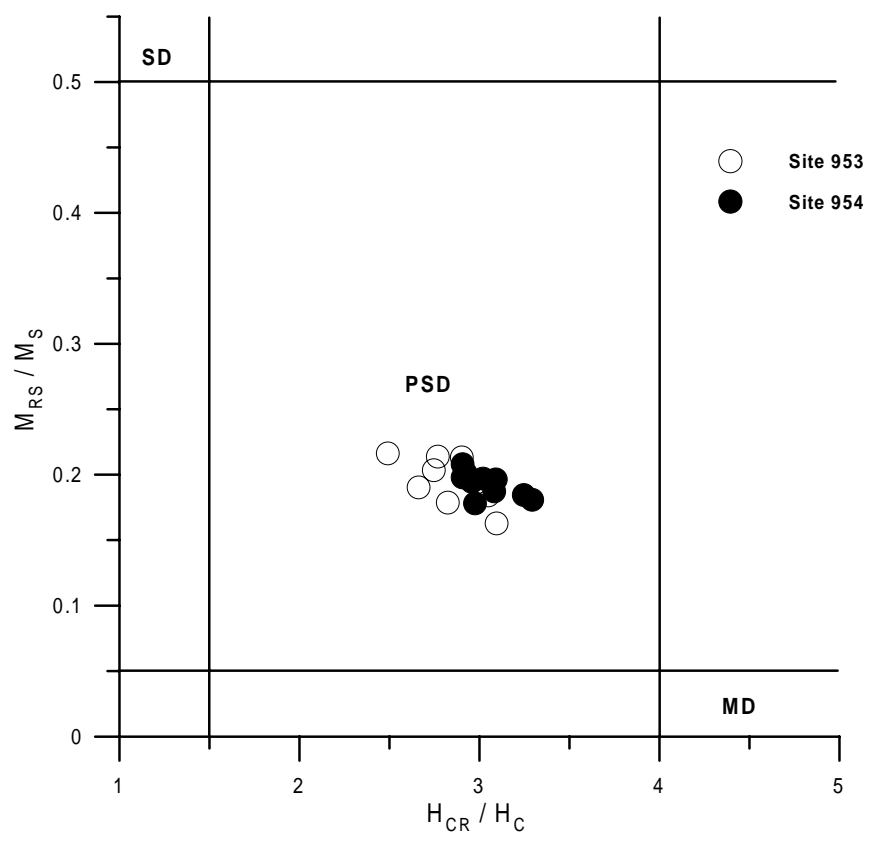

Figure 2. Domain state of the magnetic grains in a diagram after Day et al. (1977). Solid circles $=$ the domain states obtained from Site 953, and open circles $=$ the domain states obtained from Site 954. The numbers of the circles coincide with the numbers of samples presented in Tables 1 and 2. 


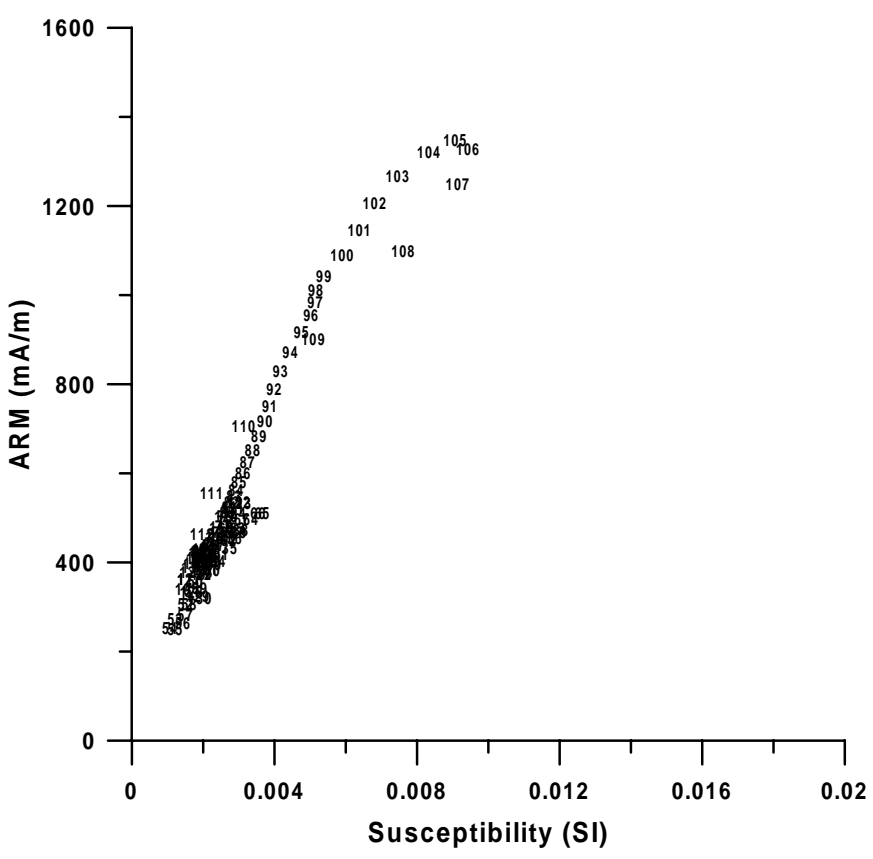

Figure 3. Diagram of ARM vs. low-field volume susceptibility after King et al. (1982) for the u-channel from Site 953. Instead of plotting symbols, the position of each measurement along the $\mathrm{u}$-channel is used.

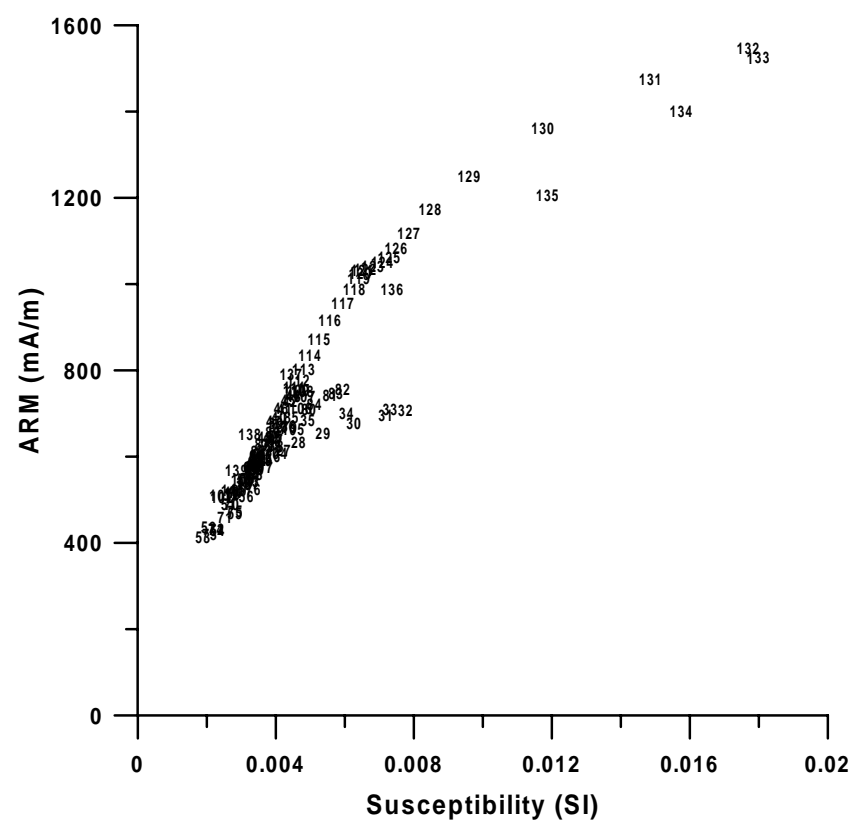

Figure 4. Diagram of ARM vs. low-field volume susceptibility after King et al. (1982) for the u-channel from Site 954.

The magnetic grain-size characteristics of Site 953 (Fig. 5) and Site 954 (Fig. 6) show some similarities around the time of the Matuyama/Brunhes transition. For instance, the maximum at $90 \mathrm{~cm}$, the minimum at $85 \mathrm{~cm}$, and the following maximum at $75 \mathrm{~cm}$ in the Site 954 records can be easily correlated to the same sequence in the Site 953 record at 70,65, and $55 \mathrm{~cm}$, respectively. However, there are also some differences regarding the magnetic grain-size variations between the two sites. For example, where ARM/IRM and $\kappa_{\mathrm{ARM}} / \mathrm{\kappa}$ are high in the sediments of Site 954 at $102 \mathrm{~cm}$, there is no spike in the

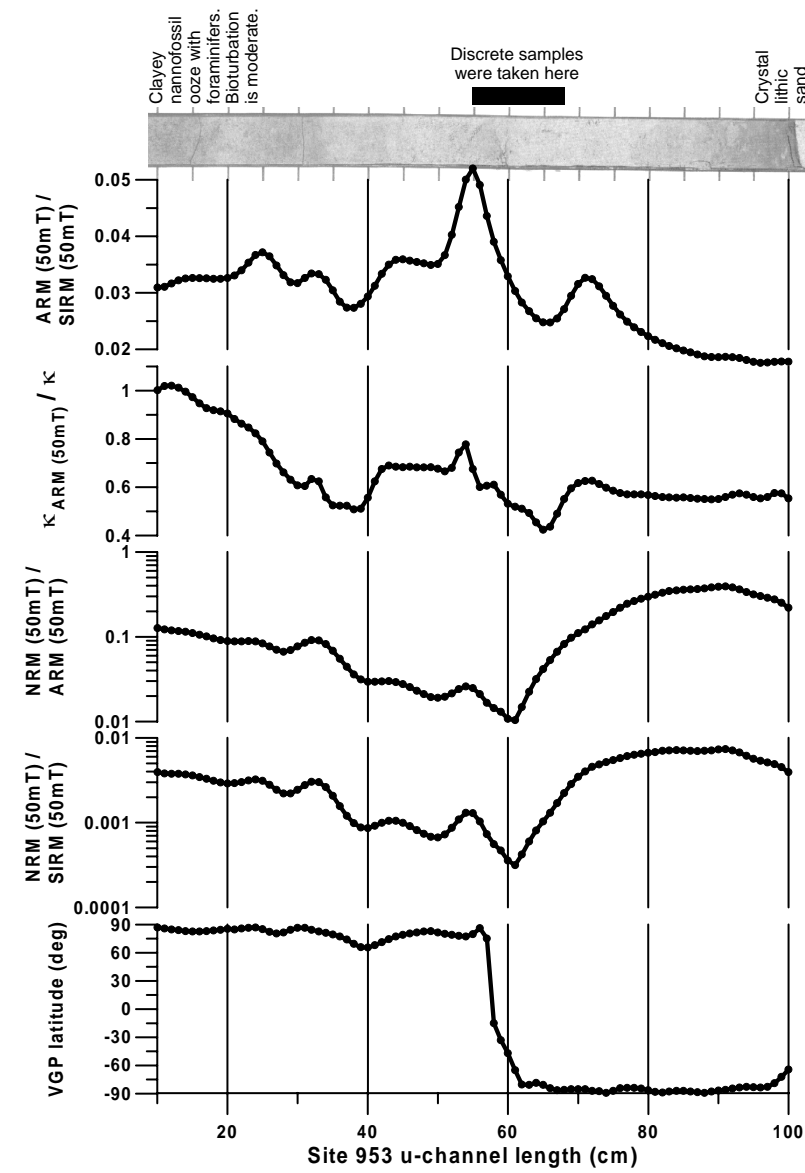

Figure 5. Magnetic grain-size variations (ARM/IRM and $\left.\kappa_{\mathrm{ARM}} / \kappa\right)$, relative paleointensity estimates (NRM/IRM and NRM/ARM), and VGP latitude for the u-channel from Section 157-953A-5H-4. A lithologic description of the section is provided at the top of the diagram. The black bar indicates the region where the discrete samples were taken.

Site 953 record. The minimum in $\kappa_{\mathrm{ARM}} / \kappa$ in the Site 954 records at 32 $\mathrm{cm}$, which is not visible in the Site 953 records, is correlated to a small crystal lithic silt layer at Site 954 and seems to be caused by changes in chemical composition. This interval is also anomalous in Figure 4, where higher susceptibility values are apparent between 28 and $35 \mathrm{~cm}$. By using the grain-size features that occur in both records, a relative sediment accumulation rate can be calculated between Sections 157-953A-5H-4 and 157-954A-7H-2. The sedimentation accumulation rate is $\sim 10 \%$ higher at Site 953 in contrast to the absolute sedimentation rates that are $\sim 8 \mathrm{~cm} / \mathrm{k}$.y. for both sites averaged over the last 2 m.y.

The relative paleointensity estimates of Sites 953 and 954 show a minimum in relative paleointensity (NRM/ARM and NRM/IRM in Figs. 5, 6) during the directional part of the transition. All four records reveal a fast pre-transitional decrease and a slow post-transitional increase in field intensity. There are some intensity fluctuations that are clearly related to variations of the magnetic grain size and not to changes in geomagnetic intensity. For example, the variations at 102, 73, and $54 \mathrm{~cm}$ in the Site 954 records can be seen in the relative paleointensity estimates as well. The latter two are also visible in the Site 953 records at 55 and $34 \mathrm{~cm}$.

\section{Discussion of Rock Magnetic Results}

The rock magnetic studies suggest a single magnetic carrier that is either magnetite or very close to magnetite in composition. The 


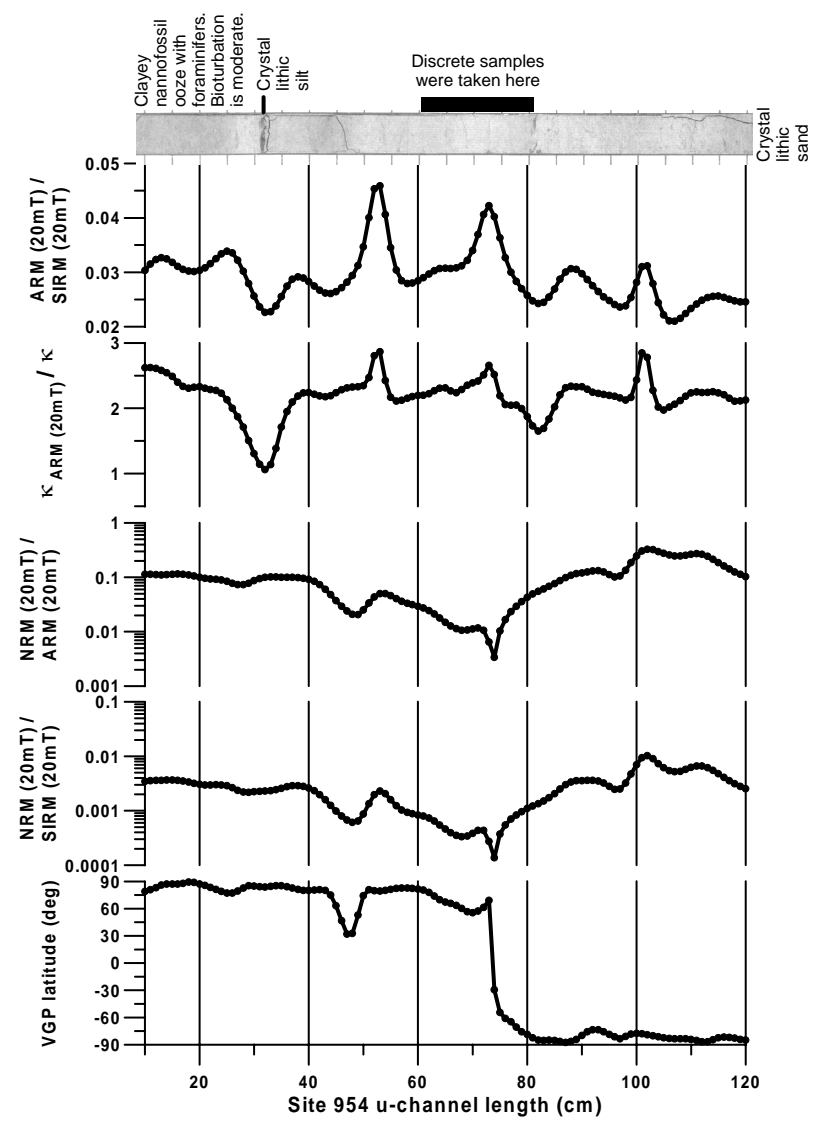

Figure 6. Parameters plotted for Section 157-954A-7H-4 as in Figure 5. A paleointensity minimum is found at the onset of the Matuyama/Brunhes transition.

depositional history of the sediment is continuous in this part of the core, except for two dark sand layers at the bottom of both sections. A dark silt layer occurs in Section 157-954A-7H-2, which neither affects the relative paleointensity estimates nor the directional behavior. Judging from the small variations of the hysteresis parameters, there seems to be a variation of grain size that clearly affects the relative paleointensity estimates. But there is at least one interval with grain-size variations in each record that does not have this influence on the relative paleointensity estimates. The nature of these two types of grain-size variability is still unclear and will be subject of further study. The results of the mineral magnetic studies identify a type of magnetic carrier that seems to be suitable for directional observations of the Matuyama/Brunhes transition.

\section{THE PALEOFIELD DIRECTION RECORDED DURING THE MATUYAMA/BRUNHES TRANSITION}

\section{Demagnetization of U-Channel Samples}

In Figures 7 and 8, the magnetic directions of each u-channel are presented as complete data sets at different demagnetization steps in stereographic projections. With this representation of the data, the magnitude of the drilling and other magnetic overprints can be estimated (see Fuller et al., Chap. 5, this volume). During progressive AF demagnetization, a component pointing steeply downward is removed. This nearly vertical magnetization is interpreted as being of drilling-induced origin. The steep component appears to be almost completely removed at 20-mT AF intensity at Site 954 , as seen from nearly antipodal directions (Fig. 8). In the u-channel at Site 953, the steep drilling overprint is not yet removed at $20 \mathrm{mT}$ and causes the "non-antipodality" of the directions before and after the reversal (Fig. 7). However, antipodality is achieved at 50-mT AF intensity at Site 953. After the demagnetization step with $50 \mathrm{mT} \mathrm{AF}$, there are spurious components that destroy the antipodality of the 20-mT demagnetization step at Site 954.

The directions of magnetization in the u-channel were studied further by analyzing demagnetization results at given positions as if they were measurements of discrete samples. This allows for the study of directional changes, demagnetization characteristics, and the use of the Zijderveld representation of magnetization directions along the uchannel. Representative examples of AF demagnetization behavior from the Matuyama and Brunhes Chrons, and a transitional interval for Site 953, are illustrated in Figure 9. For Site 954 (Fig. 10), a similar diagram with three comparable examples is presented. The illustrated declinations were reoriented by adding a constant angle to the declinations of each $\mathrm{u}$-channel such that the mean declination during the normal (reverse) chron points north (south). The Zijderveld diagrams and stereoplots in Figures 9 and 10 exhibit the same strong magnetic overprint of the NRM that was observed in the stereoplots (Figs. 7, 8) at $0 \mathrm{mT}$. The analyzed depth-slices, which acquired their magnetization during the Matuyama and Brunhes Chrons, reveal their stable component of the NRM at AF peak fields above $10 \mathrm{mT}$. For the geographic latitude of $28^{\circ} \mathrm{N}$ at both sites, one would expect an inclination of $47^{\circ}$, assuming an axial geocentric dipole field. This agrees well with the inclination of the characteristic remanence directions obtained from the depth slices of the Brunhes and Matuyama intervals. The presented transitional intervals from Holes 953A and 954A in Figures 9 and 10 do not reveal well-defined primary components of magnetization. These intervals are almost demagnetized at $20 \mathrm{mT}$, which is very low compared with the intervals before and after the transition.

\section{Demagnetization of the Discrete Samples}

To clarify the directional behavior of the transitional region, additional discrete samples were taken from the intervals indicated with the black bars presented in Figures 5 and 6 . The discrete samples were AF demagnetized with more than 20 steps each to achieve good directional control of the components of magnetization and possible magnetic overprints. The results of two representative samples from the transitional intervals at Holes 953A and at 954A are illustrated in Figure 11. The presence of a strong and steep downward-directed overprint at low AF demagnetization steps was observed again, but is not shown in the enlarged Zijderveld diagrams in Figure 11. The sample from Hole 953A (Fig. 11) has a shallow reversed direction as a primary component of magnetization. The related VGP position is $71.3^{\circ} \mathrm{S}$ and $3.7^{\circ} \mathrm{E}$ (see also Table 1). The sample from Hole 954A (Fig. 11) possesses another shallow direction of magnetization with a resulting VGP position of $28.4^{\circ} \mathrm{S}$ and $62.9^{\circ} \mathrm{E}$ (Table 2). Except for sample 9 at Site 954, a stable direction of magnetization was obtained from all of the analyzed samples taken across the Matuyama/Brunhes field transition. The directions of the stable magnetic components and the related VGP positions for the other discrete samples from Sites 953 and 954 are also listed in Tables 1 and 2.

\section{Comparison of the Transitional Records from Sites 953 and 954}

In Figures 12 and 13, the resulting VGP paths for Holes 953A (Fig. 12) and 954A (Fig. 13) are illustrated. The VGP positions of the discrete samples (open squares) coincide well with the VGP positions obtained from the u-channel (solid circles) at Site 953, except for one sample with a VGP position in the west Pacific. At Site 954, there is 


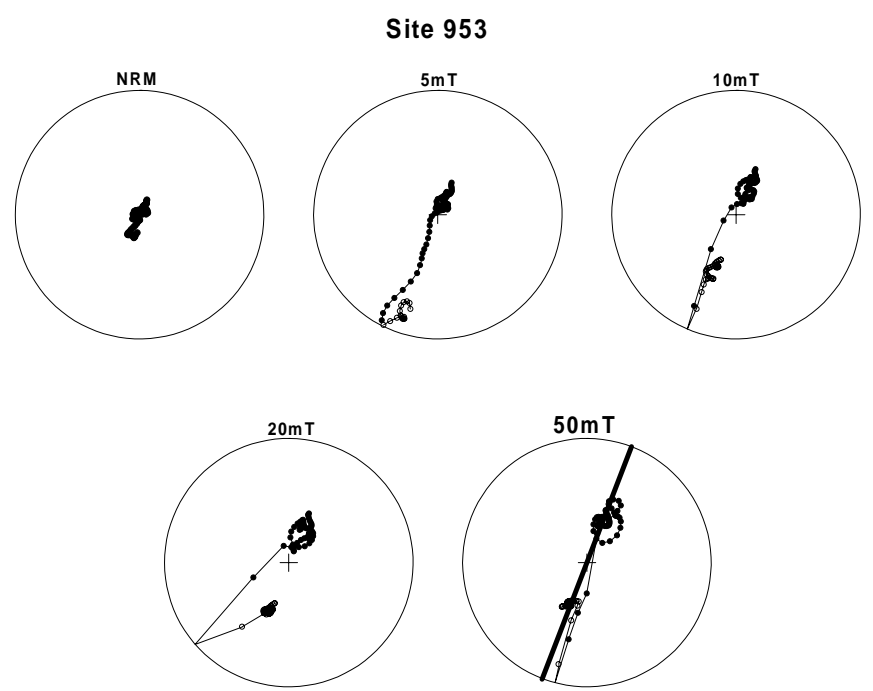

Figure 7. AF demagnetization of u-channel records for the Matuyama/Brunhes transition from Site 953. The core was not azimuthally oriented, and the declinations are not corrected. Note the strong vertical overprint that produces non-antipodality at $20 \mathrm{mT}$.
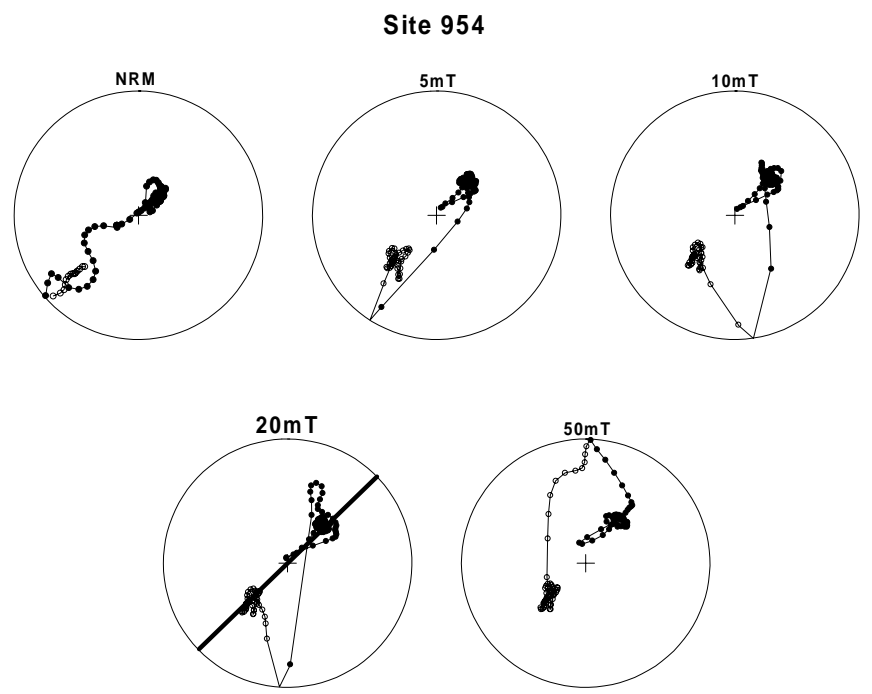

Figure 8. AF demagnetization of u-channel records of the Matuyama/Brunhes transition from Site 954 . The core was not azimuthally oriented, and the declinations are not corrected. The vertical overprint is weaker than at Site 953 , and antipodality is achieved at $20 \mathrm{mT}$.

poor agreement between data obtained from the u-channel and the discrete samples (Fig. 13).

Both VGP paths appear to be good records of the transition when considered individually. Both VGP paths start at high southern latitudes and end with well-established VGPs near the geographic north pole. A comparison of Figures 12 and 13 shows that there is a large difference of nearly $60^{\circ}$ between the two VGP paths in their longitudinal position. This difference cannot be explained by different field behavior at the two localities, because the sites are only $48 \mathrm{~km}$ apart. As discussed in the introduction, there is increasing recognition that the ODP records of reversals may be contaminated with poorly understood magnetic noise. Moreover, the records from the two holes are quite dissimilar, although they were collected within a few tens of kilometers of each other, and therefore, should have been exposed to the same sequence of geomagnetic field changes. To resolve this discrepancy, the records from Holes 953A and 954A have been subjected to additional analysis.

\section{Discrete Samples}

In principle, the discrete samples should be easier to interpret because their signal is not convolved as it is the case with the $\mathrm{u}$-channel measurements. The resolution is only related to the diameter of the samples. The discrete samples had to be taken closer to the margin of the core, because the u-channel had already been taken from the central part of the working half. According to Bleil (1989), the drill moment influences are larger at the periphery of the cores because of the proximity from the magnetic field in the advanced piston core (APC) barrels (Fuller et al., Chap. 5, this volume). At Site 954, there is clear evidence of drilling-produced moments in the discrete samples, as described below.

Samples were taken from both sides of the u-channels. In our convention they are described as left-hand side (LHS) or right-hand side (RHS) looking down the core (Fig. 14). The two sets of coordinate systems that were used for the discrete samples and for the u-channels are presented in Figure 14. The sequence of the discrete samples in Site 954 is thus LHS $61.60-68.8 \mathrm{~cm}$ (the position of the upper sample margin), whereas the remaining six samples alternate between RHS and LHS (see also Table 2). Systematic differences between LHS and RHS samples are seen in the characteristic remanence directions of samples 5(RHS), 6(LHS), 7(RHS), 8(LHS), 9(RHS), and 10(LHS) (Fig. 15). In the stereoplot, the directions of the RHS samples are always shifted in the $+Y$ direction, whereas the LHS samples are shifted in the $-Y$ direction. Figure 15 is in sample coordinates before correction for the orientation of the APC core to magnetic north. The upcore and other key directions are marked on the plot. A horizontal radially inward-directed drill moment points along the $270^{\circ}(-\mathrm{Y})$ direction in the LHS samples and in the $90^{\circ}(+\mathrm{Y})$ direction in the RHS samples. A radial drilling overprint therefore points in opposite directions on the left- and righthand side of the u-channel. One can observe that the measured directions of the illustrated samples from Site 954 in Figure 15 are displaced to the $+\mathrm{Y}$ and $-\mathrm{Y}$ direction as if there is a strong horizontal radial component directed inward.

By using a vector sum and difference technique, analogous to that used for the Thellier intensity method for determining paleointensities, we can, in principle, separate the radially drilling-produced magnetization from the remaining paleomagnetic signal, which points in opposite directions in the LHS and RHS samples. These vector calculations were carried out with samples 7(RHS) and 8(LHS) from Site 954 (Fig. 15). We then find that the difference in directions between these samples is predominantly along the Y-axis and of the magnitude $3.03 \mathrm{~mA} / \mathrm{m}$, whereas the common magnetization is 2.02 $\mathrm{mA} / \mathrm{m}$. The declination of the common magnetization in samples 7 and 8 is $220^{\circ}$, and the inclination is $45.5^{\circ}$. The difference vector is therefore in the direction of the drilling-induced magnetization, and the sum vector of the components is in a direction lying between the two initial directions of the two samples. In the discrete samples from 953A, a fairly similar effect is seen, but it is much smaller. It can however be seen in Figure 16, which is analogous to Figure 15. In Site 953, it is much harder to distinguish whether there is a shifting to either the $+Y$ direction in the RHS samples or to the $-Y$ direction in the LHS samples respectively, which was introduced by radially drilling-produced magnetization. However, at both sites, the NRM was initially almost in the vertically downward direction. While in Hole 954A during demagnetization, the magnetization rapidly moves away from the vertically downcore direction, and the samples with the number 1 (RHS) to 5(LHS) from Hole 953A remain steeply inclined during demagnetization. In contrast, the magnetization of the samples from 6(LHS) to 10(RHS) departs from vertically downward upon demagnetization. Moreover, the NRM and ARM vs. IRM 


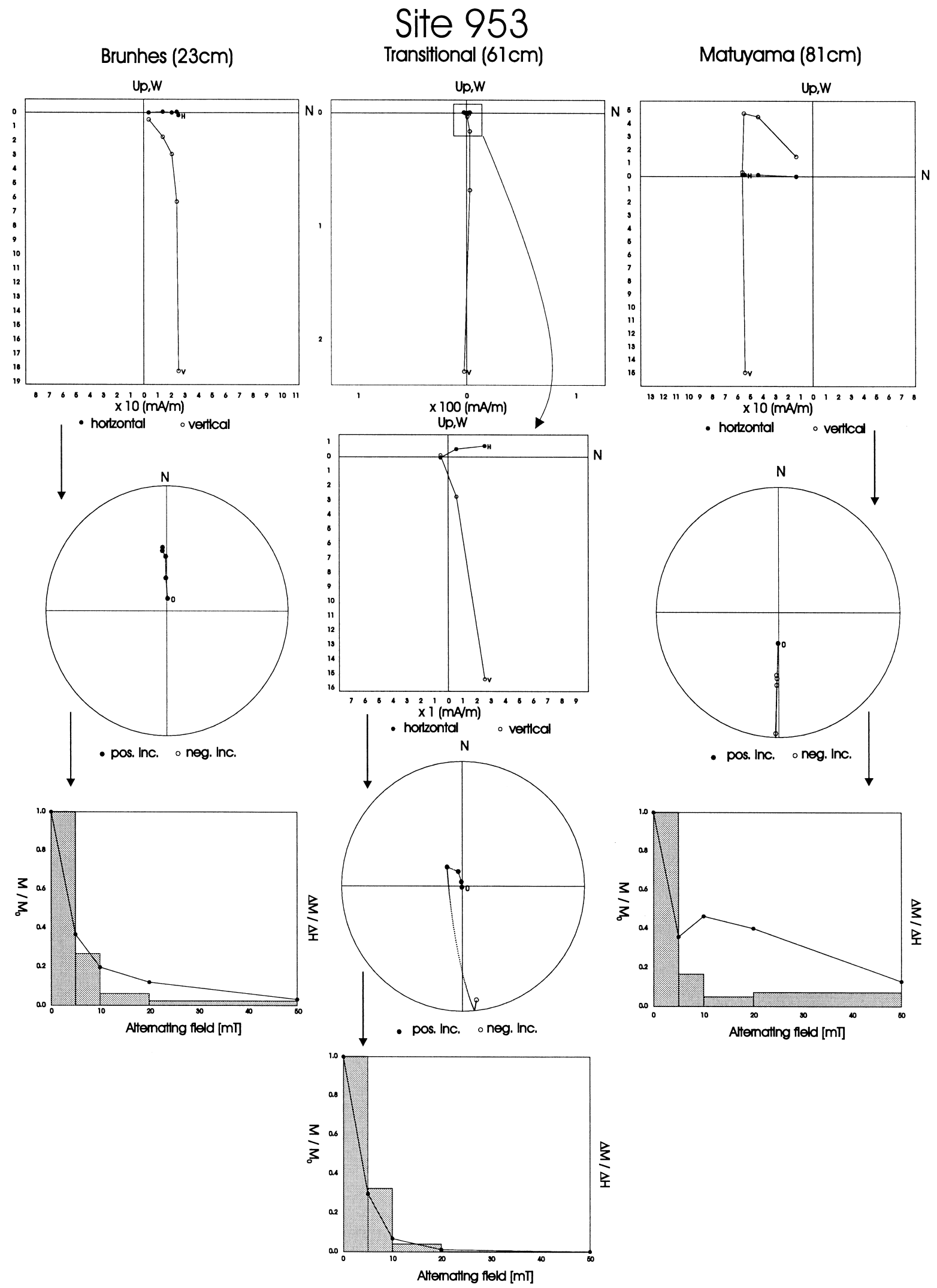

Figure 9. Zijderveld plots, stereoplots, and demagnetization diagrams determined for discrete positions along the u-channel from Site 953 . The strong vertical overprint is evident at all illustrated positions. In the Brunhes and Matuyama Chron samples, a stable direction converges to the origin between $20 \mathrm{mT}$ and 50 $\mathrm{mT}$. 
Site 954

Brunhes $(21 \mathrm{~cm})$

Transitional $(74 \mathrm{~cm})$

Matuyama $(113 \mathrm{~cm})$
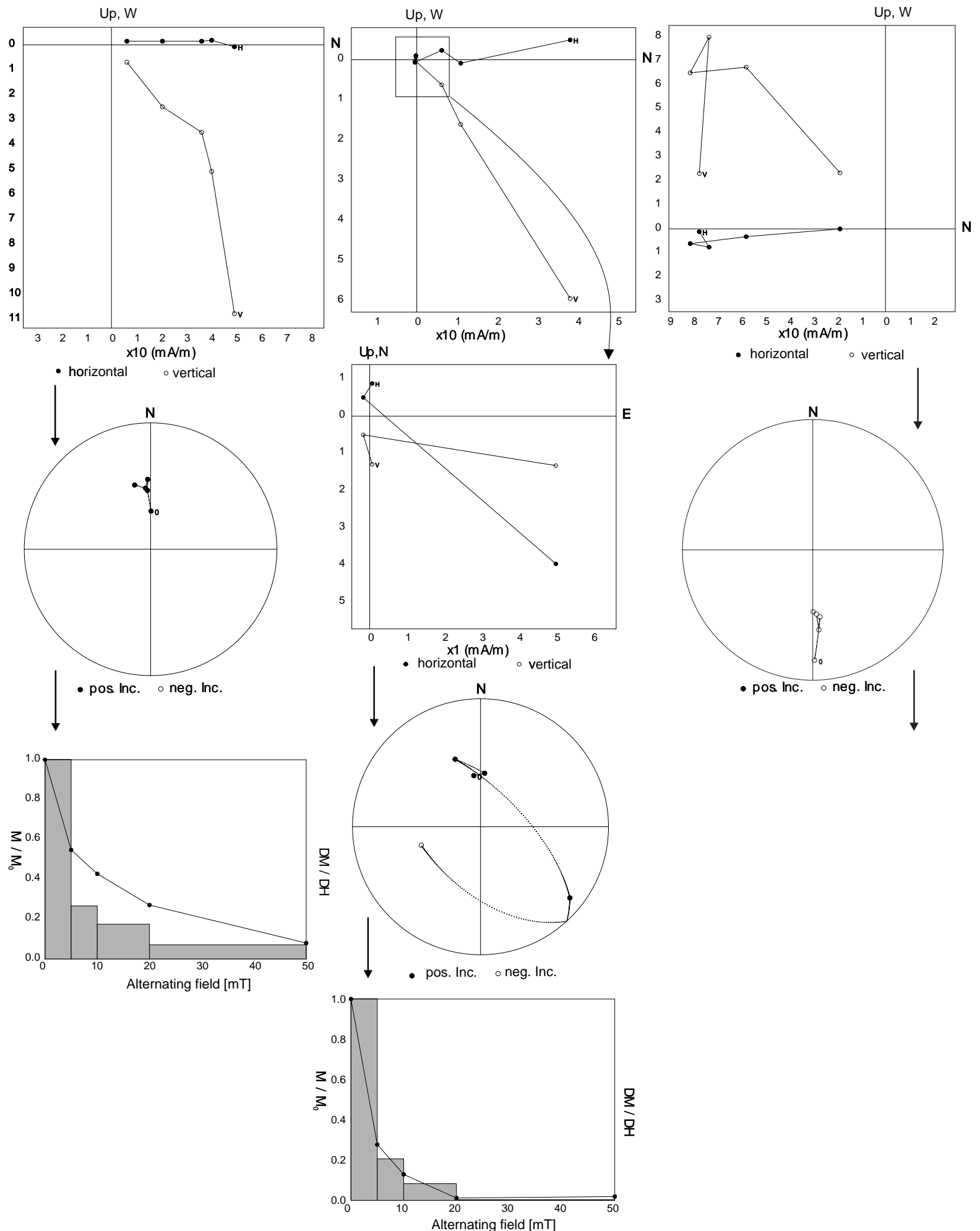

Figure 10. Zijderveld plots, stereoplots, and demagnetization diagrams determined for discrete positions along the u-channel from Site 954 . The vertical overprint is weaker in this site than at Site 953. A stable magnetic direction is evident for the Brunhes and Matuyama Chrons. 
Hole 953A

Sample 62.0-63.8
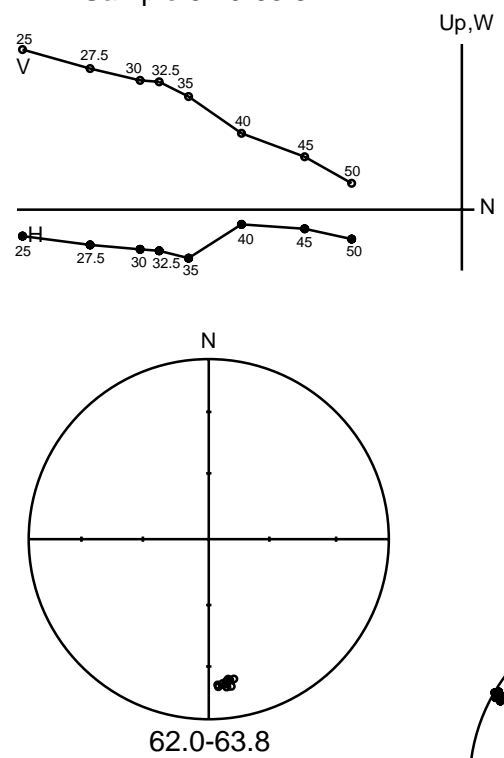

62.0-63.8
Hole 954A

Sample 70.8-72.6
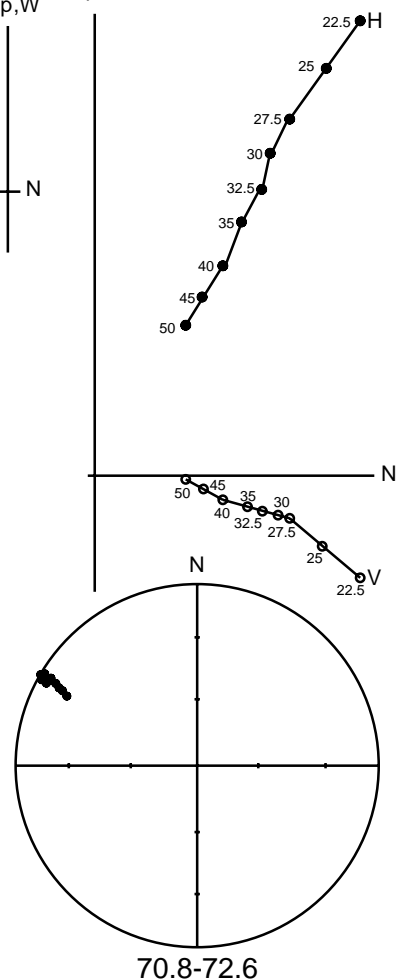

Figure 11. Typical AF demagnetization results from discrete samples taken adjacent to the u-channel samples from Holes 953A and 954A. Demagnetization steps are given in mT. The low field demagnetization steps are not shown because of strong vertical magnetic overprints.

demagnetization plots of the samples 6 through 10 show a distinct change in slope. An example is given in Figure 17 at the bottom. In low alternating fields $<15 \mathrm{mT}$, the NRM demagnetization curve falls rapidly, whereas for higher fields, it follows the convex up-curve of ARM demagnetization. In the samples where the vertically downward magnetization persists ( 1 to 5 ), the demagnetization curves are more continuous and weakly concave up (Fig. 17, top).

Whether the radial drilling-induced moment in these samples is a simple IRM acquired in the magnetic field of the APC core barrel, or a moment more directly related to the drilling process in the presence of a field is not immediately clear. However, by analogy with the magnetization of the Leg 157 wash core experiment reported in Fuller et al. (Chap. 5, this volume), it is more likely to be the latter. There it is demonstrated that an IRM of at least $50 \mathrm{mT}$ is necessary to generate demagnetization characteristics that are comparable to the NRM demagnetization behavior, but this IRM would be several times stronger in its initial intensity. The IRM with an intensity comparable to the NRM intensity is much softer in its demagnetization characteristics. The drilling overprint can therefore not be a simple IRM.

AMS studies were carried out on the discrete samples to analyze whether there are any anisotropy effects visible in the alignment of the magnetic grains. The results for Site 953 are illustrated in Figure 18 and for Site 954 in Figure 19, respectively. Both illustrations are given in the same sample coordinates as Figures 15 and 16. The bedding plane corresponds to the $\mathrm{Y}-\mathrm{Z}$ plane in the diagrams. In both stereoplots, a strict sorting effect between RHS and LHS samples is visible. The maximum $\mathrm{K} 1$-axis is tilted from the bedding plane downward. While the K1-axis of the LHS samples is clustering in the $2^{\text {nd }}$ quadrant between $90^{\circ}$ and $180^{\circ}$, the RHS samples are clustering in the $3^{\text {rd }}$ quadrant between $180^{\circ}$ and $270^{\circ}$. A similar sorting effect is visible at the minimum axis (Fig. 18). Below the stereoplots, Flinn diagrams are given in Figures 18 and 19, which reveal a mainly oblate shape of the susceptibility ellipsoids. This sorting effect of the AMS into LHS and RHS samples can be explained by tilting effects in this part of the core, where the discrete samples were taken or by realignment effects of the magnetic grains. A possibility for realignment would be dewatering because of the high pressure that occurs during APC coring when the core barrel is "shot" hydraulically into the sediment. This coring technique is also responsible for the wellknown bending and smear effects at the margins of the APC cores. Whether this AMS anomaly can be responsible for radial magnetization effects will be subject of further studies. But it is clearly shown that mechanical influences on the outer parts and possibly on the inner parts of the core are quite important to be understood for transitional studies with ODP material.

To conclude, the analysis of the discrete sample results from Holes 953A and 954A yields the following results. First, the Hole 954A samples are strongly contaminated with a horizontal radial drilling-produced magnetization that is pointing inward. The Hole 953A samples show far less radial drill contamination, but the samples from Hole 953A show stronger vertical drill contamination, which dominates the magnetization of the samples from 54.9 to $59.1 \mathrm{~cm}$, whose demagnetization characteristics are similar having concave continuous up-curves. In contrast, the samples from 60.6 to $66.0 \mathrm{~cm}$ show shallow reversed directions and demagnetization curves that fall steeply to $\sim 15 \mathrm{mT}$ and then flatten with concave upcurves very similar to the ARM demagnetization curves.

Second, at both sites, the AMS measurements show a strange sorting effect into samples that were taken from the right-hand side of the core (by looking downward) and from the left-hand side. The maximum axis of the susceptibility ellipsoid is tilted out of the bedding plane.

\section{U-Channel Samples}

The u-channel data are paradoxical. They give two records of the Matuyama/Brunhes reversal that are distinctly different; the sites are within a few tens of kilometers and therefore should have been exposed to the same sequence of field changes. Either one or both records are invalid paleomagnetic records. The next question to be settled is whether either record is reliable.

Hole 953A has a strong vertical contamination that is dominant before demagnetization. During demagnetization, the vertical moment becomes less obvious, and at $50 \mathrm{mT}$, it is less important to give rise to non-antipodality in the directions before and after the reversal (Fig. 7). However, during the actual transition, the directions of magnetization recorded by successive intervals of the u-channel pass through a direction vertically downward beneath the site (Fig. 12). The u-channel from Site 954 does not have such a strong vertical overprint, and the directions at $20 \mathrm{mT}$ are obviously antipodal. To test whether either of these records is a genuine sequence of field directions, or a further manifestation of the vertical or radial drill moment, we have tried to estimate the drill moment in the u-channel samples.

Because we do not have the u-channel record from the archived half of the core to provide the analogue of our RHS and LHS discrete samples, we have extended the earlier test of antipodality to provide an estimate of the magnetic overprint. This makes the assumption that away from the reversal, the magnetic field should be dipolar and the normal and reversed directions should be antipodal. The occurrence of magnetic overprints should disturb the antipodality of the reversal. In the case of a horizontal radial drill overprint, which is directed inward, this departure from antipodality will take the form of a contribution in the $+\mathrm{X}$ direction, because the $\mathrm{u}$-channels were not taken from the center of the whole core with regard to the $\mathrm{X}$-axis in 
Table 1. Characteristic remanence directions of single samples taken from Section $157-953 \mathrm{~A}-5 \mathrm{H}-4\left(28^{\circ} 42^{\prime} \mathrm{N}, 1^{\circ} 12^{\prime} \mathrm{W}\right)$.

\begin{tabular}{ccccccc}
\hline Sample & $\begin{array}{c}\text { Interval } \\
(\mathrm{cm})\end{array}$ & $\begin{array}{c}\text { Position } \\
(\text { view downcore) }\end{array}$ & $\begin{array}{c}\text { Declination } \\
\left({ }^{\circ}\right)\end{array}$ & $\begin{array}{c}\text { Inclination } \\
\left({ }^{\circ}\right)\end{array}$ & $\begin{array}{c}\text { VGP latitude } \\
\left({ }^{\circ}\right)\end{array}$ & $\begin{array}{c}\text { VGP longitude } \\
\left({ }^{\circ}\right)\end{array}$ \\
\hline 1 & $54.9-56.7$ & LHS & 190.4 & 44.8 & 34.1 & 153.6 \\
2 & $56.1-57.9$ & RHS & 182.9 & 82.8 & 14.5 & 344.2 \\
3 & $57.4-59.2$ & LHS & 165.8 & 72.4 & -2.9 & 352.5 \\
4 & $58.4-60.2$ & RHS & 170.6 & 61.9 & -17.8 & 352.1 \\
5 & $59.1-60.9$ & LHS & 161.2 & 47.1 & -30.3 & 004.1 \\
6 & $60.6-62.4$ & RHS & 190.5 & -30.0 & -74.2 & 304.8 \\
7 & $62.0-63.8$ & LHS & 174.0 & -20.8 & -71.3 & 003.7 \\
8 & $63.2-65.0$ & RHS & 194.0 & -30.4 & -72.2 & 295.4 \\
9 & $64.6-66.4$ & LHS & 179.8 & -22.4 & -73.1 & 345.7 \\
10 & $66.0-67.8$ & RHS & 181.4 & -36.0 & -81.3 & 336.3 \\
\hline
\end{tabular}

Table 2. Characteristic remanence directions of single samples taken from Section $157-954 \mathrm{~A}-7 \mathrm{H}-2\left(28^{\circ} 24^{\prime} \mathrm{N}, 1^{\circ} 30^{\prime} \mathrm{W}\right)$,

\begin{tabular}{ccccccc}
\hline Sample & $\begin{array}{c}\text { Interval } \\
(\mathrm{cm})\end{array}$ & $\begin{array}{c}\text { Position } \\
(\text { view downcore })\end{array}$ & $\begin{array}{c}\text { Declination } \\
\left({ }^{\circ}\right)\end{array}$ & $\begin{array}{c}\text { Inclination } \\
\left({ }^{\circ}\right)\end{array}$ & $\begin{array}{c}\text { VGP latitude } \\
\left({ }^{\circ}\right)\end{array}$ & $\begin{array}{c}\text { VGP longitude } \\
\left({ }^{\circ}\right)\end{array}$ \\
\hline 1 & $61.6-63.4$ & LHS & 001.6 & 32.6 & 79.2 & 156.4 \\
2 & $64.5-66.3$ & LHS & 351.4 & 53.0 & 81.0 & 292.0 \\
3 & $66.8-68.6$ & LHS & 329.8 & 45.9 & 64.4 & 259.1 \\
4 & $68.8-70.6$ & LHS & 298.0 & -6.4 & -22.6 & 057.3 \\
5 & $70.8-72.6$ & RHS & 300.2 & 8.1 & -28.4 & 062.9 \\
6 & $72.5-74.3$ & LHS & 178.2 & 57.5 & -23.4 & 346.1 \\
7 & $74.0-75.8$ & RHS & 230.3 & 31.2 & -23.6 & 291.0 \\
8 & $75.5-77.3$ & LHS & 170.1 & 42.5 & -36.2 & 355.7 \\
9 & $77.1-78.9$ & RHS & $-\overline{143.2}$ & -35.7 & -55.5 & 068.3 \\
10 & $78.6-80.4$ & LHS & 143.2 & -35.5 & \\
\hline
\end{tabular}

Note: No stable direction of magnetization was obtained from sample 9.
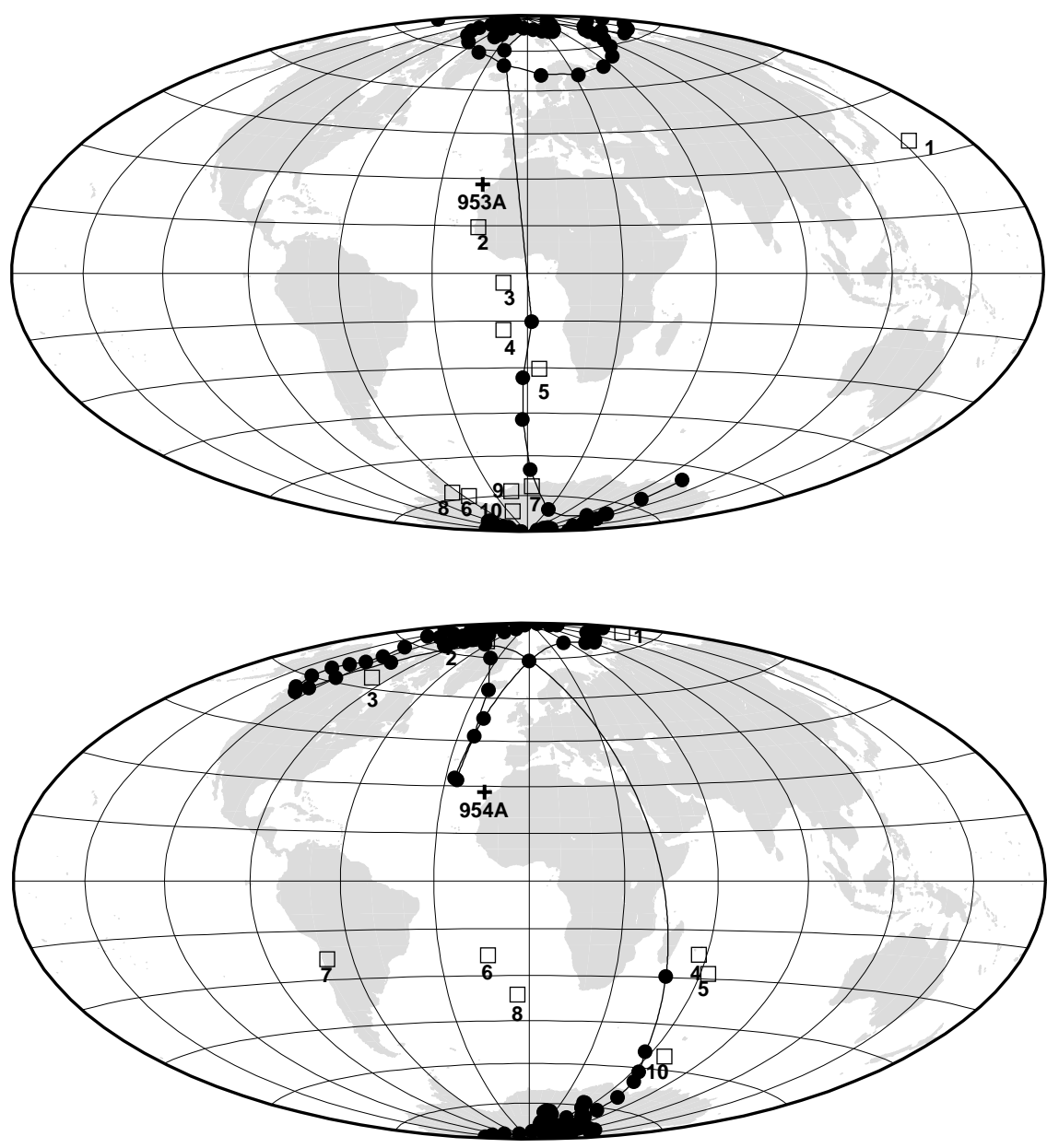

Figure 12. VGP path for Hole 953A (plus sign) from u-channel measurements (solid circles) and discrete samples (open squares). The meaning of the numbers is described in Table 1. The VGPs obtained from the discrete samples agree well with the u-channel measurements.

Figure 13. VGP path for Hole 954A (same conventions as Fig. 12). The meaning of the numbers is described in Table 2. The VGP path is offset more than $45^{\circ}$ to the east in comparison to Hole 953A. The VGPs obtained from the discrete samples do not coincide with the u-channel measurements. 


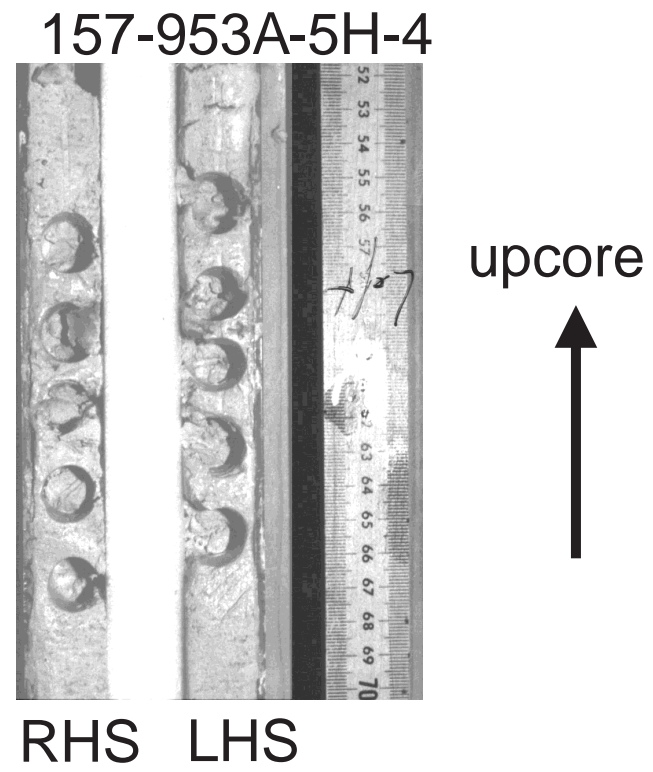

\section{Sample coordinates}
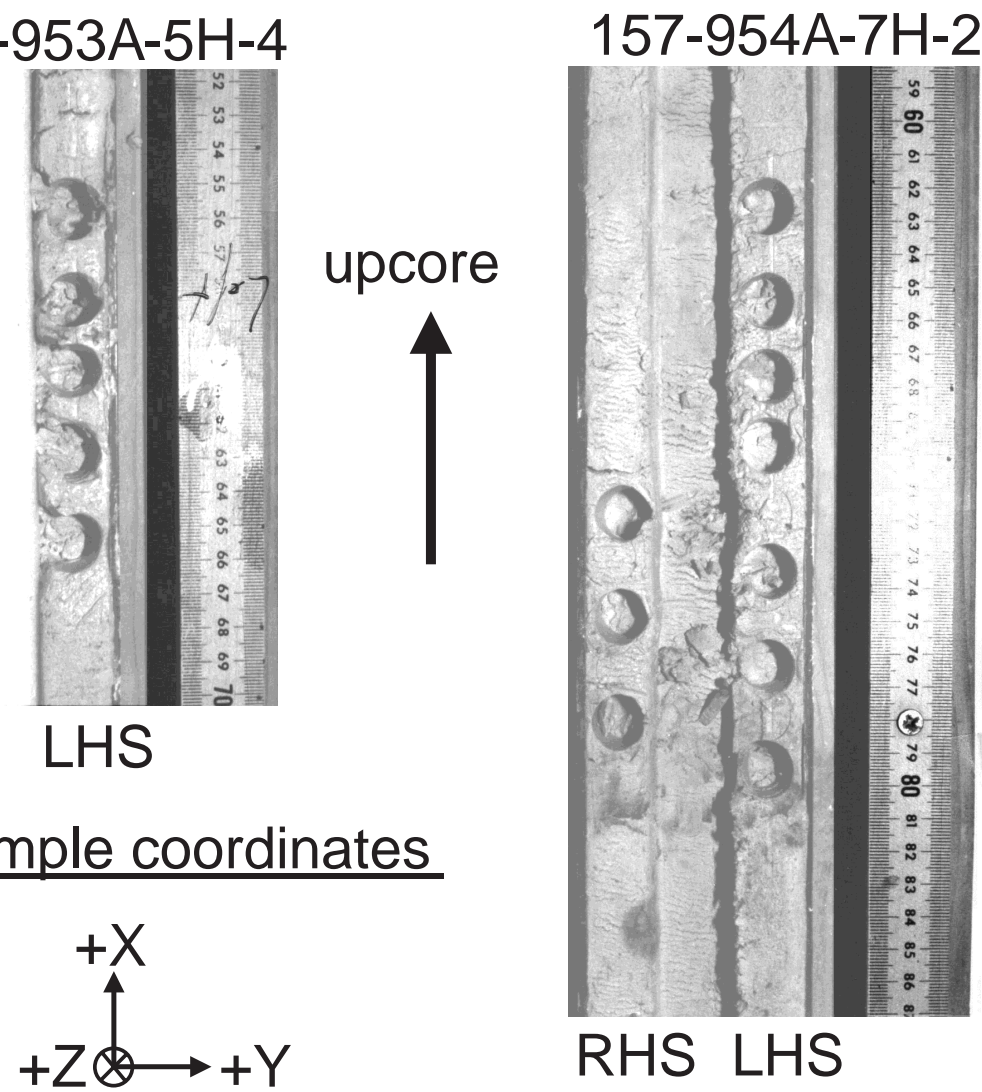

\section{ODP coordinates for the working half}

Figure 14. Illustration of the core sections from Holes 953A and 954A, where the discrete samples were taken. The left-hand side (LHS) and the right-hand side (RHS) definitions of the samples, which were taken from opposite sides of the u-channels, are given. The sample coordinates, as well as the ODP coordinates for the working halves are illustrated.

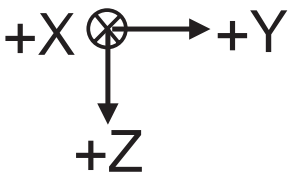

ference of 0.01 for the $\mathrm{X}$ unit vectors is very small. At Site 954 (Table 4), there is lesser vertical overprint at the $0 \mathrm{mT}$ demagnetization step compared with Site 953. Almost perfect antipodality with regard to the means of the $\mathrm{Y}$ unit vectors is reached at $20 \mathrm{mT}$ (see also Fig. 8), with a difference of 0.01 . At this demagnetization step, the difference of the $\mathrm{X}$ unit vectors is 0.04 , which can be interpreted as the influence of drilling-produced horizontal radial magnetization that has resisted $\mathrm{AF}$ demagnetization. However, the difference of the mean $\mathrm{Z}$ unit vectors is 0.06 and exceeds the difference of the $X$ unit vectors. Because a horizontal overprint cannot affect the $\mathrm{Z}$ component of magnetization in ODP coordinates, we interpret this result as a vertical overprint that resisted the AF demagnetization process in Site 954 and is from the same magnitude as the horizontal radial overprint.

This result is surprising. We expected more radial magnetization influence at Site 954 as we have seen quite severely in the directions obtained from the discrete samples. When comparing the results from Sites 953 and 954, it is difficult to distinguish whether there are any significant effects of horizontal radial overprints or whether the discrepancies are because of magnetic noise that results from antipodal geomagnetic field behavior. Actually, the difficulty of the test of the antipodality to detect drilling overprints is the use of core intervals that are free from non-antipodal field influences. However, there are 


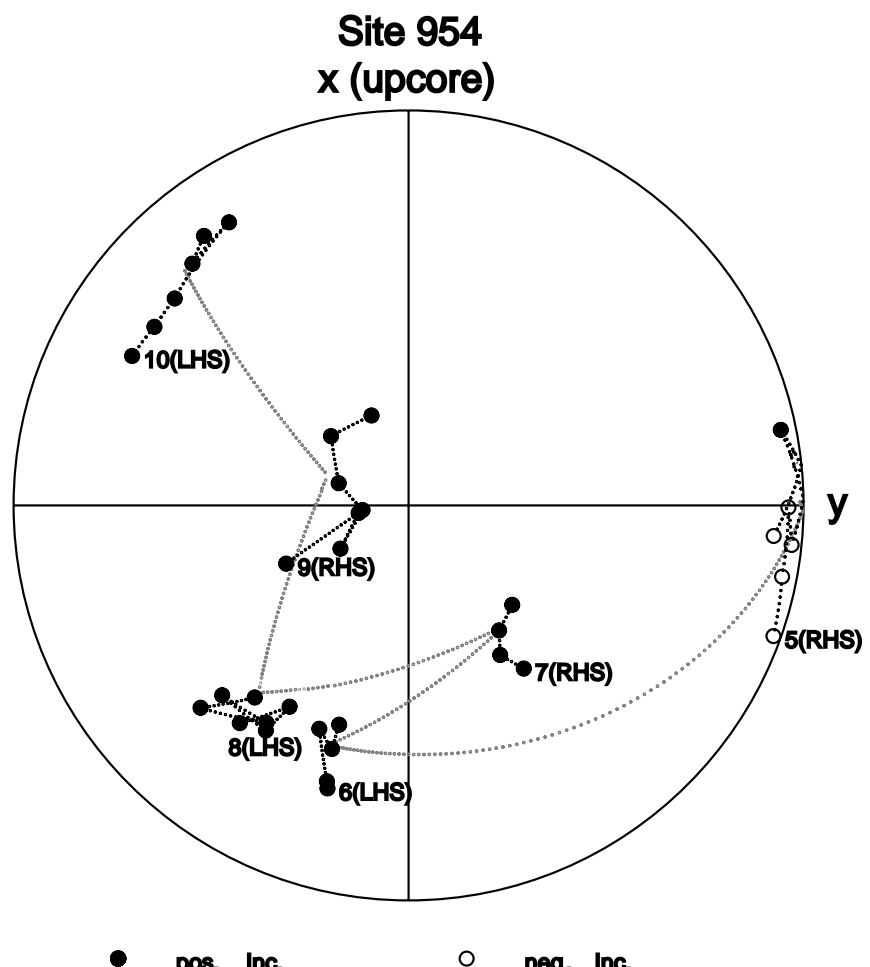

Figure 15. Stereographic projection of the demagnetization steps of the discrete samples from Site 954 carrying the "characteristic remanence direction" given in sample coordinates. The samples from the right-hand side of the core (looking upcore) are systematically moved to the $+\mathrm{Y}$ direction. The samples from the opposite side of the core are moved to the $-\mathrm{Y}$ direction. This shifting is because of a horizontal radial inward-directed magnetization in the working half from Site 954.

always antipodal field effects, especially in the vicinity of geomagnetic transitions that make the performed test inaccurate. To solve this problem and to clarify the possibility of the occurrence of drilling-produced horizontal radial magnetization effects in ODP cores, the u-channel from the archived half of the same core should be measured. If the obtained VGP path is identical with the path obtained from the working half, this test would show that the VGP paths are free from drilling-produced magnetization, which affects the horizontal components of the NRM.

\section{CONCLUSIONS}

The analysis of these two paleomagnetic records of the Matuyama/Brunhes transition have raised important questions concerning the interpretation of the stable directions of ODP advanced piston cores. The results indicate that the remanence of the discrete samples taken alongside of the $\mathrm{u}$-channels is strongly contaminated with a horizontal magnetization directed radially inward and with a vertical magnetization. The radial magnetization could be determined at Site 954 in two samples, because the samples were taken from both sides of the u-channel. The radially inward magnetization was in opposite directions in samples from opposite sides of the u-channel. A test of antipodality was introduced to detect drilling overprints in the $\mathrm{u}-$ channels.

At Site 954, the radial magnetization appears to be present in the u-channel combined with a hard vertical overprint. However, this test depends upon the strict assumption that the VGPs of the field before

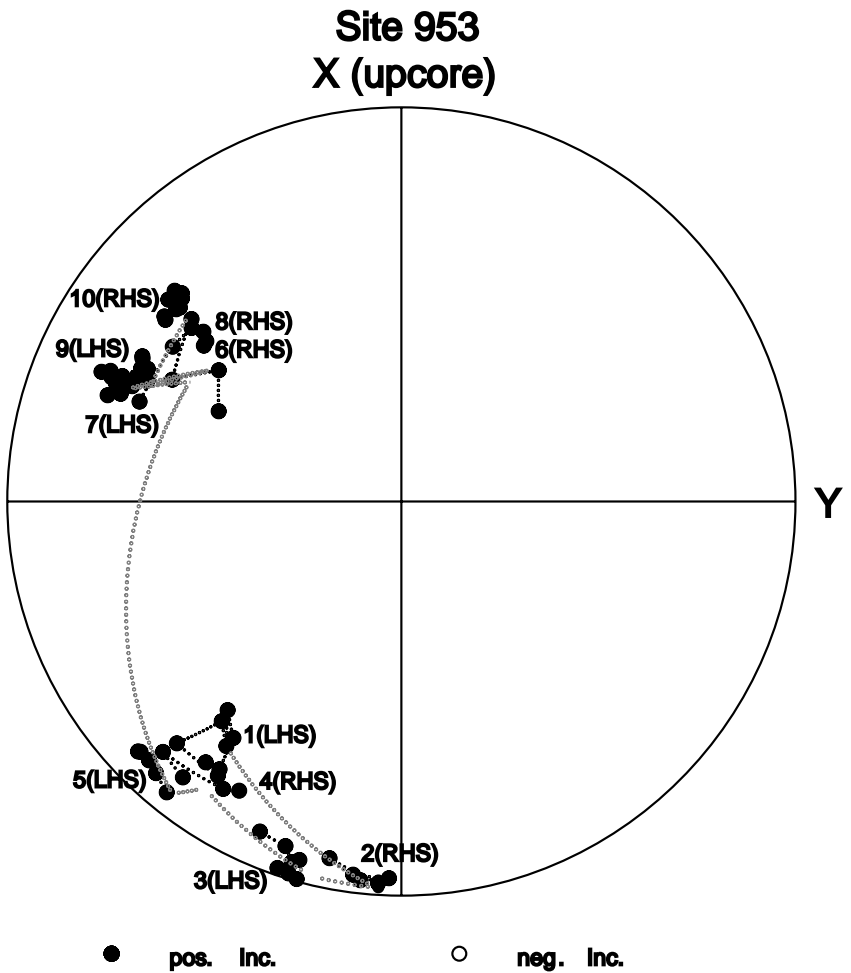

Figure 16. Stereographic projection of the samples from Site 953 using the same conventions as in Figure 15. The radial magnetization effect is much less evident in the discrete samples from Site 953 than at Site 954.

and after the field transition are perfectly antipodal. A test that is independent of the criterion of antipodality would be to compare the record from the archived half with the record obtained from the working half of the same core. We will request permission to sample the archived halves for this test. Such a test would be analogous to the test used on the discrete samples. The possible presence of drillingproduced remanence in some reversal records, and the ability to introduce false intermediate points into geomagnetic transitional records, demands caution in the interpretation of ODP reversal records that have not been adequately tested for such moments. Another characteristic of the horizontal radial magnetization is that it seems to appear in combination with the realignment of the magnetic grains. Whether realignment of magnetic grains in the presence of a radial field of the drilling gear is the source of the radial magnetization remains unclear and is subject to further study.

\section{ACKNOWLEDGMENTS}

We thank Dr. Catherine Kissel for parts of the u-channels measurements in Gif-Sur-Yvette. We would also like to acknowledge the help we had received on the JOIDES Resolution and in the Bremen core repository, as well as support from ODP in both Germany and Texas. This work was funded by grants from the Deutsche Forschungsgemeinschaft (DFG) and the National Science Foundation (NSF).

\section{REFERENCES}

Bleil, U., 1989. Magnetostratigraphy of Neogene and Quaternary sediment series from the Norwegian Sea: Ocean Drilling Program, Leg 104. In Eldholm, O., Thiede, J., Taylor, E., et al., Proc. ODP, Sci. Results, 104: College Station, TX (Ocean Drilling Program), 829-901. 
Bloemendal, J., King, J.W., Hall, F.R., and Doh, S.-J., 1992. Rock magnetism of late Neogene and Pleistocene deep-sea sediments: relationship to sediment source, diagenetic processes, and sediment lithology. J. Geophys. Res., 97:4361-4375.

Clement, B.M., 1991. Geographical distribution of transitional VGPs: evidence for non-zonal equatorial symmetry during the Matuyama-Brunhes geomagnetic reversal. Earth Planet. Sci. Lett., 104:48-58.

Day, R., Fuller, M., and Schmidt, V.A., 1977. Hysteresis properties of titanomagnetites: grain-size and compositional dependence. Phys. Earth Planet. Inter, 13:260-267.

Kent, D.V., and Schneider, D.A., 1995. Correlation of paleointensity variation records in the Brunhes/Matuyama polarity transition interval. Earth Planet. Sci. Lett., 129:135-144.

King, J., Banerjee, S.K., Marvin, J., and Özdemir, Ö., 1982. A comparison of different magnetic methods for determining the relative grain size of magnetite in natural materials: some results from lake sediments. Earth Planet. Sci. Lett., 59:404-419.

Laj, C., Mazaud, A., Fuller, M., Weeks, R., and Herrero-Bervera, E., 1991. Lateral variations at the core-mantle boundary revealed by geomagnetic reversal paths? Nature, 351:447.

Laj, C., Mazaud, A., Weeks, R., Fuller, M., and Herrero-Bervera, E., 1992. Statistical assessment of the preferred longitudinal bands for recent geomagnetic reversal records. Geophys. Res. Lett., 19:2003-2006.

Langereis, C.G., van Hoof, A.A.M., and Rochette, P., 1992. Longitudinal confinement of geomagnetic reversal paths: sedimentary artifact or true field behavior. Nature, 358:226-229.

McFadden, P.L., Barton, C.E., and Merrill, R.T., 1993. Do virtual geomagnetic poles follow preferred paths during geomagnetic reversals? Nature, $361: 342-344$

Quidelleur, X., and Valet, J.-P., 1994. Paleomagnetic records of excursions and reversals possible biases caused by magnetization artifacts. Phys. Earth Planet. Inter., 82:27-48.

Roberts, A.P., Stoner, J.S., and Richter, C., 1996. Coring induced magnetic overprints and limitations of the long-core paleomagnetic measurements technique: some observations from Leg 160, eastern Mediterranean Sea. In Emeis, K.-C., Robertson, A.H.F., Richter, C., et al., Proc. ODP, Init. Repts., 160: College Station, TX (Ocean Drilling Program), 497-505.

Shipboard Scientific Party, 1995. Site 926. In Curry, W.B., Shackleton, N.J., Richter, C., et al., Proc. ODP, Init. Repts., 154: College Station, TX (Ocean Drilling Program), 153-232.

Tauxe, L., 1993. Sedimentary records of relative paleointensity of the geomagnetic field: theory and practice. Rev. Geophys., 31:319-354.

Tric, E., Laj, C., Jehanno, C., Valet, J.-P., Kissel, C., Mazaud, A., and Iccarino, S., 1991. High-resolution record of the Upper Olduvai transition from Po Valley (Italy) sediments: support for dipolar transition geometry? Phys. Earth Planet. Int., 65:319-336.

Valet, J.-P., Tucholka, P., Courtillot, V., and Meynadier, L., 1992. Palaeomagnetic constraints on the geometry of the geomagnetic field during reversals. Nature, 356:400-407.

Weeks, R., Lay, C., Endignoux, L., Fuller, M., Roberts, A., Manganne, R., Blanchard, E., and Goree, W., 1993. Improvements in long-core measurement techniques: applications in paleomagnetism and paleoceanography. Geophys. J. Int., 114:651-662.

Date of initial receipt: 8 July 1996

Date of acceptance: 22 January 1997 Ms 157SR-105
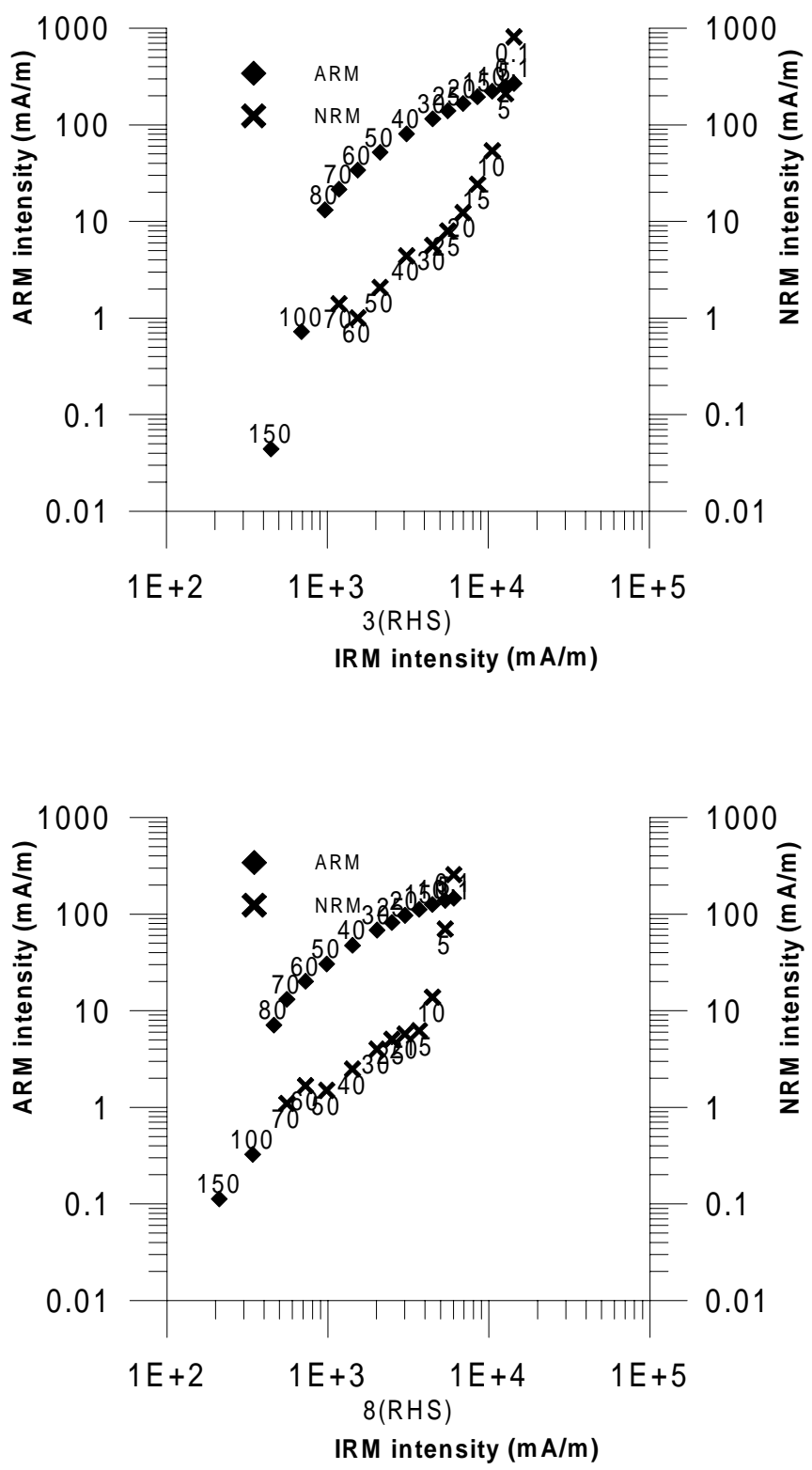

Figure 17. ARM and NRM intensities of two representative samples of the Brunhes and the Matuyama Chrons from Site 953 plotted vs. IRM intensity. The sample from the Matuyama Chron (bottom) shows a distinct change in slope. In the samples where the vertically downward magnetization persists (top), the demagnetization curves are more continuous and weakly concave up. 

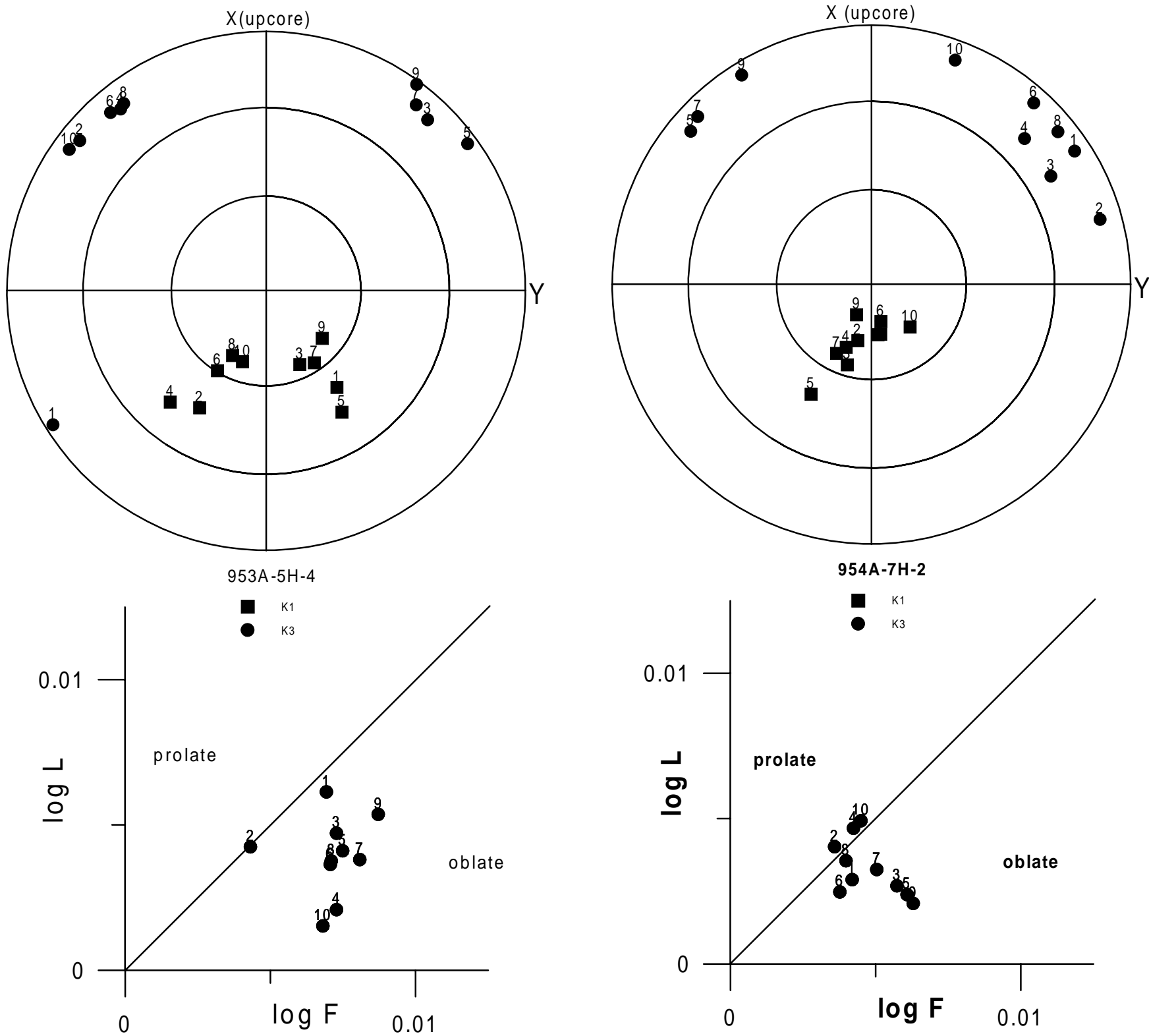

Figure 18. Stereographic projection of the AMS measurements of Site 953 illustrated in sample coordinates. Top: The bedding plane of the sediment is in the $\mathrm{Y}-\mathrm{Z}$ plane of the diagram. Bottom: Lineation is plotted vs. foliation in a Flinn diagram. The directions of the maximum as well as the directions of the minimum axis show a strong sorting effect into LHS and RHS samples. The shape of the susceptibility ellipsoid is mainly oblate as indicated in the Flinn diagram.

Table 3. Calculated mean values of the $X, Y$, and $Z$ unit vectors of the magnetization from the Brunhes and Matuyama interval of Section 157953A-5H-4 during stepwise demagnetization.

\begin{tabular}{clrrrrr}
\hline $\begin{array}{c}\text { Mean unit } \\
\text { vectors }\end{array}$ & Chron & $0 \mathrm{mT}$ & $5 \mathrm{mT}$ & $10 \mathrm{mT}$ & $20 \mathrm{mT}$ & $50 \mathrm{mT}$ \\
\hline $\mathrm{X}$ & Brunhes & 0.07 & 0.20 & 0.38 & 0.45 & 0.59 \\
$\mathrm{X}$ & Matuyama & -0.23 & -0.80 & -0.72 & -0.64 & -0.58 \\
$\mathrm{Y}$ & Brunhes & 0.04 & 0.10 & 0.18 & 0.22 & 0.27 \\
$\mathrm{Y}$ & Matuyama & -0.06 & -0.26 & -0.27 & -0.24 & -0.23 \\
$\mathrm{Z}$ & Brunhes & 0.99 & 0.97 & 0.90 & 0.85 & 0.73 \\
$\mathrm{Z}$ & Matuyama & 0.96 & 0.21 & -0.60 & -0.72 & -0.77 \\
& & & & & & \\
\hline
\end{tabular}

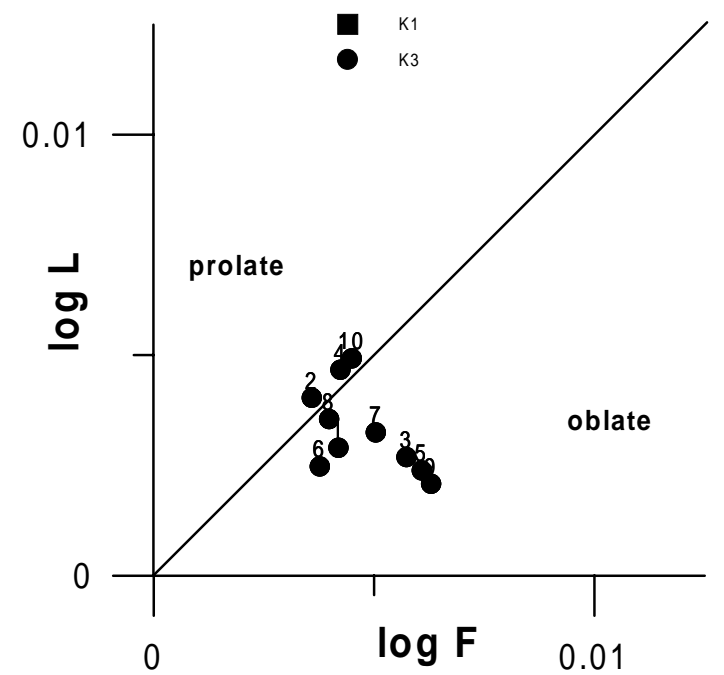

Figure 19. Stereographic projection of the AMS measurements of Site 954 using the same conventions as in Figure 18. A sorting effect of the obtained directions is evident between the samples taken from the left-hand side and the right-hand side of the core.

Table 4. Calculated mean values of the $X, Y$, and $Z$ unit vectors of the magnetization from the Brunhes and Matuyama interval of Section 157954A-7H-2 during stepwise demagnetization.

\begin{tabular}{clrrrrr}
\hline $\begin{array}{c}\text { Mean unit } \\
\text { vectors }\end{array}$ & Chron & $0 \mathrm{mT}$ & $5 \mathrm{mT}$ & $10 \mathrm{mT}$ & $20 \mathrm{mT}$ & $50 \mathrm{mT}$ \\
\hline X & Brunhes & 0.27 & 0.44 & 0.42 & 0.55 & 0.72 \\
X & Matuyama & -0.44 & -0.59 & -0.50 & -0.51 & -0.46 \\
Y & Brunhes & 0.27 & 0.46 & 0.46 & 0.50 & 0.35 \\
Y & Matuyama & -0.56 & -0.52 & -0.38 & -0.49 & -0.50 \\
$\mathrm{Z}$ & Brunhes & 0.92 & 0.76 & 0.76 & 0.63 & 0.42 \\
$\mathrm{Z}$ & Matuyama & 0.36 & -0.59 & -0.46 & -0.69 & -0.72 \\
\hline
\end{tabular}

